\begin{tabular}{c}
$\begin{array}{c}\text { Brazilian Journal } \\
\text { of Chemical } \\
\text { Engineering }\end{array}$ \\
\hline
\end{tabular}

ISSN 0104-6632

Printed in Brazil

www.abeq.org.br/bjche

Vol. 25, No. 04, pp. 613 - 630, October - December, 2008

\title{
A REVIEW ON NANOFLUIDS - PART I: THEORETICAL AND NUMERICAL INVESTIGATIONS
}

\author{
Xiang-Qi Wang and Arun S. Mujumdar ${ }^{1}$ \\ Department of Mechanical Engineering, National University of Singapore, \\ Phone: +(65) 6874-4623, Fax: +(65) 6779-1459, \\ 10 Kent Ridge Crescent, 119260, Singapore. \\ E-mail: mpeasm@nus.edu.sg
}

(Received: January 2, 2008 ; Accepted: May 20, 2008)

\begin{abstract}
Research in convective heat transfer using suspensions of nanometer-sized solid particles in base liquids started only over the past decade. Recent investigations on nanofluids, as such suspensions are often called, indicate that the suspended nanoparticles markedly change the transport properties and heat transfer characteristics of the suspension. This first part of the review summarizes recent research on theoretical and numerical investigations of various thermal properties and applications of nanofluids.

Keywords: Nanofluids; Nanoparticles; Heat transfer; Thermal conductivity.
\end{abstract}

\section{INTRODUCTION}

Convective heat transfer can be enhanced passively by changing flow geometry, boundary conditions, or by enhancing thermal conductivity of the fluid. Various techniques have been proposed to enhance the heat transfer performance of fluids. Researchers have also tried to increase the thermal conductivity of base fluids by suspending micro- or larger-sized solid particles in fluids, since the thermal conductivity of solid is typically higher than that of liquids, as seen from Table 1. Numerous theoretical and experimental studies of suspensions containing solid particles have been conducted since Maxwell's theoretical work was published more than 100 years ago (Maxwell, 1881). However, due to the large size and high density of the particles, there is no good way to prevent the solid particles from settling out of suspension. The lack of stability of such suspensions induces additional flow resistance and possible erosion. Hence, fluids with dispersed coarsegrained particles have not yet been commercialized.

Table 1: Thermal conductivities of various solids and liquids

\begin{tabular}{|l|r|r|}
\hline & Material & Thermal Conductivity (W/m-K) \\
\hline \multirow{2}{*}{ Metallic solids } & copper & 401 \\
& aluminum & 237 \\
\hline \multirow{2}{*}{ Nonmetallic solids } & silicon & 148 \\
\hline Metallic liquids & alumina $\left(\mathrm{Al}_{2} \mathrm{O}_{3}\right)$ & 40 \\
\hline \multirow{2}{*}{ Nonmetallic liquids } & sodium $(644 \mathrm{~K})$ & 0.613 \\
& water & 0.253 \\
\hline
\end{tabular}

*To whom correspondence should be addressed 
Modern nanotechnology provides new opportunities to process and produce materials with average crystallite sizes below $50 \mathrm{~nm}$. Fluids with nanoparticles suspended in them are called nanofluids, a term proposed in 1995 by Choi of the Argonne National Laboratory, U.S.A. (Choi, 1995). Nanofluids can be considered to be the nextgeneration heat transfer fluids because they offer exciting new possibilities to enhance heat transfer performance compared to pure liquids. They are expected to have superior properties compared to conventional heat transfer fluids, as well as fluids containing micro-sized metallic particles. The much larger relative surface area of nanoparticles, compared to those of conventional particles, should not only significantly improve heat transfer capabilities, but also should increase the stability of the suspensions. Also, nanofluids can improve abrasion-related properties as compared to the conventional solid/fluid mixtures. Successful employment of nanofluids will support the current trend toward component miniaturization by enabling the design of smaller and lighter heat exchanger systems. Keblinski et al. (2005), in an interesting review, discussed the properties of nanofluids and future challenges. The development of nanofluids is still hindered by several factors such as the lack of agreement between results, poor characterization of suspensions, and the lack of theoretical understanding of the mechanisms.

Suspended nanoparticles in various base fluids can alter the fluid flow and heat transfer characteristics of the base fluids. Necessary studies need to be carried out before wide application can be found for nanofluids. In this paper we present an overview of the literature dealing with recent developments in the study of heat transfer using nanofluids. First, the preparation of nanofluids is discussed; this is followed by a review of recent experimental and analytical investigations with nanofluids.

\section{THEORETICAL INVESTIGATIONS}

\section{Mechanisms of Nanofluids}

The conventional understanding of the effective thermal conductivity of mixtures originates from continuum formulations which typically involve only the particle size/shape and volume fraction and assume diffusive heat transfer in both fluid and solid phases. This method can give a good prediction for micrometer or lager-size solid/fluid systems, but it fails to explain the unusual heat transfer characteristics of nanofluids.

The present understanding of thermal transport in nanofluids can be grouped into two categories. Some postulate that the thermal conductivity of nanofluids is composed of the particle's conventional static part and a Brownian motion part which produces micromixing. These models take the particle dynamics into consideration, whose effect is additive to the thermal conductivity of a static dilute suspension. Thus, the particle size, volume fraction, thermal conductivities of both the nanoparticle and the base fluid, and the temperature itself are taken into account in such models for the thermal conductivity of nanofluids. These theories provide a means of understanding the particle interaction mechanism in nanofluids.

Other groups have started from the nanostructure of nanofluids. These investigators assume that the nanofluid is a composite, formed by the nanoparticle as a core, and surrounded by a nanolayer as a shell, which in turn is immersed in the base fluid, and from which a three-component medium theory for a multiphase system is developed. Some have suggested that the enhancement is due to the ordered layering of liquid molecules near the solid particles. The mechanism for thermal conduction between a liquid and a solid is not clear.

To explain the reasons for the anomalous increase of the thermal conductivity in nanofluids, Keblinski et al. (2002) and Eastman et al. (2004) proposed four possible mechanisms, e.g., Brownian motion of the nanoparticles, molecular-level layering of the liquid at the liquid/particle interface, the nature of heat transport in the nanoparticles, and the effects of nanoparticle clustering, which are schematically shown in Fig. 1. They postulated that the effect of Brownian motion can be ignored, since the contribution of thermal diffusion is much greater than Brownian diffusion. However, they only examined the cases of stationary nanofluids. Wang et al. (1999) argued that the thermal conductivities of nanofluids should be dependent on the microscopic motion (Brownian motion and inter-particle forces) and particle structure. Xuan and Li (2000) also discussed four possible reasons for the improved effective thermal conductivity of nanofluids: the increased surface area due to suspended nanoparticles, the increased thermal conductivity of the fluid, the interaction and collision among particles, the intensified mixing fluctuation and turbulence of the fluid, and the dispersion of nanoparticles. 


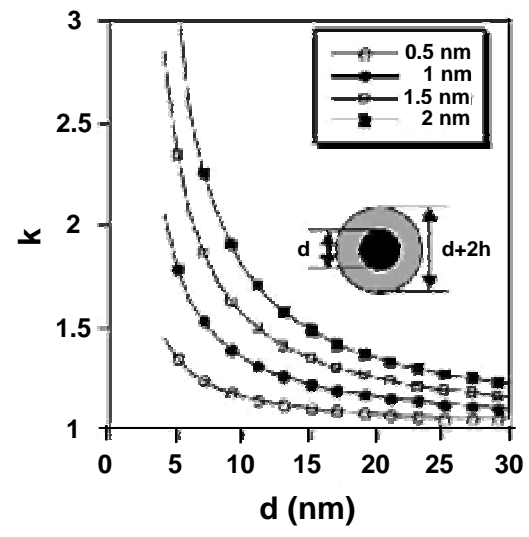

(a)

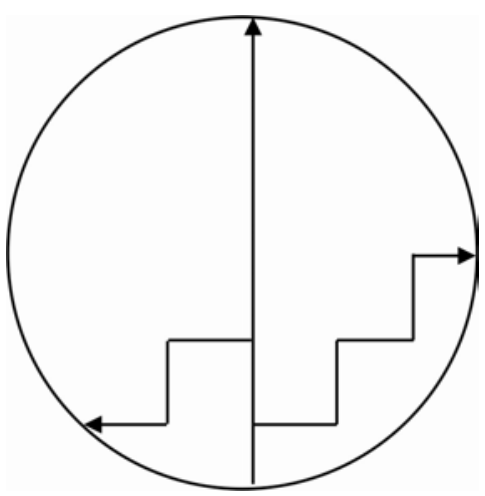

(b)

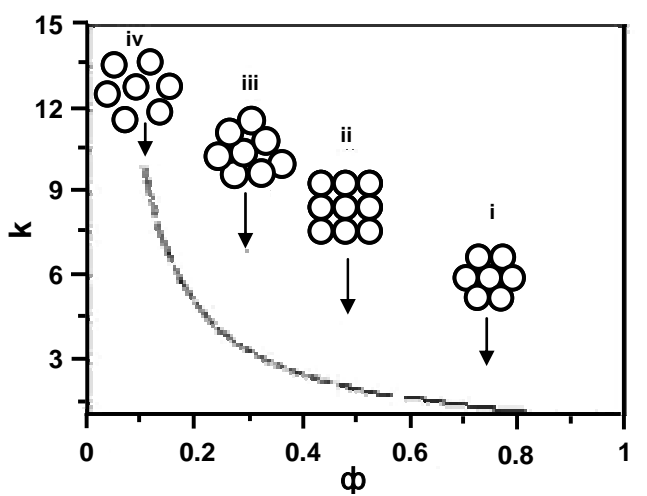

(c)

Figure 1: Schematic diagrams of several possible mechanisms (Keblinski et al., 2002): (a) Enhancement of $\mathrm{k}$ due to formation of highly conductive layer-liquid structure at the liquid/particle interface;

(b) Ballistic and diffusive phonon transport in a solid particle; (c)Enhancement of $\mathrm{k}$ due to increased effective $\phi$ of highly conducting clusters

Many researchers used the concept of liquid/solid interfacial layer to explain the anomalous improvement of the thermal conductivity in nanofluids. Yu and Choi $(2003,2004)$ suggested models, based on conventional theory, which consider a liquid molecular layer around the nanoparticles. However, a study of Xue et al. (2004) using molecular dynamics simulation showed that simple monatomic liquids had no effect on the heat transfer characteristics both normal and parallel to the surface. This means that thermal transport in a layered liquid may not be adequate to explain the increased thermal conductivity of suspensions of nanoparticles.

Khaled and Vafai (2005) investigated the effect of thermal dispersion on heat transfer enhancement of nanofluids. These results showed that the presence of the dispersive elements in the core region did not affect the heat transfer rate. However, the corresponding dispersive elements resulted in $21 \%$ improvement of the Nusselt number for a uniform tube supplied by a fixed heat flux as compared to the uniform distribution for the dispersive elements. These results provide a possible explanation for the increased thermal conductivity of nanofluids, which may be determined partially by the dispersive properties.

Wen and Ding (Wen and Ding, 2005; Ding and Wen, 2005) studied theoretically the effect of particle migration on heat transfer characteristics in nanofluids flowing through mini-channels ( $\mathrm{D}=1 \mathrm{~mm})$. They studied the effect of shearinduced and viscosity-gradient-induced particle migration and the self-diffusion due to Brownian motion. Their results indicated a significant nonuniformity in particle concentration and thermal conductivity over the tube cross-section due to particle migration. Compared to the uniform distribution of thermal conductivity, the nonuniform distribution caused by particle migration induced a higher Nusselt number. 
Koo and Kleinstreuer (2005a) discussed the effects of Brownian, thermo-phoretic, and osmo-phoretic motions on the effective thermal conductivities. They found that the role of Brownian motion is much more important than the thermo-phoretic and osmo-phoretic motions. Furthermore, the particle interaction can be neglected when the nanofluid concentration is low $(<$ $0.5 \%$ ). However, these findings have not been validated by experiment yet.

Tillman and Hill (2007) attempted to find a more systematic procedure to determine the nanolayer thickness and the thermal conductivity profile within the nanolayer. Three basic heat conduction regions were used to derive the expression for the nanolayer thickness. Despite the results obtained from the thermal boundary resistance studied by experiments, the existing theoretical studies of the solid-liquid interface of a nanoparticle are still in the ongoing development phase.

Evans et al. (2006) suggested that the contribution of Brownian motion to the thermal conductivity of the nanofluid is very small and cannot be responsible for the extraordinary thermal transport properties of nanofluids. They also supported their argument by using molecular dynamics simulations and the effective medium theory. However, they just limited their discussion to stationary fluids, which weakens their conclusions.

Rather than Brownian motion, liquid layering, phonon transport, and agglomeration, Lee et al. (2006) experimentally investigated the effect of surface charge state of the nanoparticle in suspension on the thermal conductivity. They showed that the $\mathrm{pH}$ value of the nanofluid strongly affected the thermal performance of the fluid. The further the $\mathrm{pH}$ value diverged from the isoelectric point of the particles, the more stable the nanoparticles in the suspension and greater the change in the thermal conductivity. That may partially explain the disparities between different experimental data since many researchers used surfactants in nanofluids, but with insufficient descriptions. By adopting a variation of the classical heat conduction method in porous media to the problem of heat conduction in nanofluids, Vadasz (2006) demonstrated that the transient heat conduction process in nanofluids may provide a valid alternative explanation for the apparent heat transfer enhancement.

Hence, so far there are no general mechanisms to rationalize the strange behavior of nanofluids, including the highly improved effective thermal conductivity, although many possible factors have been considered, including Brownian motion, liquidsolid interface layer, ballistic phonon transport, and surface charge state. However, there are still several other possible macro-scale explanations such as heat conduction, particle-driven natural convection, convection induced by electrophoresis, thermophoresis, etc.

\section{Density and Specific Heat}

The calculation of the effective density $\rho_{\text {eff }}$ and the effective specific heat $\mathrm{C}_{\mathrm{p} \text {,eff }}$ of a nanofluid is straightforward. The can be estimated based on the physical principle of the mixture rule as

$$
\begin{aligned}
\rho_{\text {eff }}=\left(\frac{m}{V}\right)_{\text {eff }}=\frac{m_{b}+m_{p}}{V_{b}+V_{p}}= \\
=\frac{\rho_{b} V_{b}+\rho_{p} V_{p}}{V_{b}+V_{p}}=\left(1-\phi_{p}\right) \rho_{b}+\phi_{b} \rho_{p} \\
\left(\rho C_{p}\right)_{\text {eff }}=\rho_{\text {eff }}\left(\frac{Q}{m \Delta T}\right)_{\text {eff }}=\rho_{\text {eff }} \frac{Q_{b}+Q_{p}}{\left(m_{b}+m_{p}\right) \Delta T}= \\
=\rho_{\text {eff }} \frac{\left(m C_{p}\right)_{b} \Delta T+\left(m C_{p}\right)_{p} \Delta T}{\left(m_{b}+m_{p}\right) \Delta T}= \\
=\rho_{\text {eff }} \frac{\left(\rho C_{p}\right)_{b} V_{b}+\left(\rho C_{p}\right)_{p} V_{p}}{\rho_{b} V_{b}+\rho_{p} V_{p}}= \\
=\left(1-\phi_{p}\right)\left(\rho C_{p}\right)_{b}+\phi_{p}\left(\rho C_{p}\right)_{p}
\end{aligned}
$$

which can be rewritten as

$\mathrm{C}_{\mathrm{p}, \mathrm{eff}}=\frac{\left(1-\phi_{\mathrm{p}}\right)\left(\rho \mathrm{C}_{\mathrm{p}}\right)_{\mathrm{b}}+\phi_{\mathrm{p}}\left(\rho \mathrm{C}_{\mathrm{p}}\right)_{\mathrm{p}}}{\left(1-\phi_{\mathrm{p}}\right) \rho_{\mathrm{b}}+\phi_{\mathrm{p}} \rho_{\mathrm{p}}}$

\section{Thermal Conductivity}

Currently, there is no reliable theory to predict the anomalous thermal conductivity of nanofluids. From the experimental results of many researchers, it is known that the thermal conductivity of nanofluids depends on parameters including the thermal conductivities of the base fluid and the nanoparticles, the volume fraction, the surface area, and the shape of the nanoparticles, and the temperature. There are no theoretical formulas currently available to predict the thermal conductivity of nanofluids satisfactorily.

However, there exist several semi-empirical correlations for calculating the apparent conductivity 
of two-phase mixtures. They are mainly based on the following definition of the effective thermal conductivity of a two-component mixture

$$
\mathrm{k}_{\text {eff }}=\frac{\mathrm{k}_{\mathrm{p}} \phi_{\mathrm{p}}(\mathrm{dT} / \mathrm{dx})_{\mathrm{p}}+\mathrm{k}_{\mathrm{b}} \phi_{\mathrm{b}}(\mathrm{dT} / \mathrm{dx})_{\mathrm{b}}}{\phi_{\mathrm{p}}(\mathrm{dT} / \mathrm{dx})_{\mathrm{p}}+\phi_{\mathrm{b}}(\mathrm{dT} / \mathrm{dx})_{\mathrm{b}}}
$$

For particle-fluid mixtures, numerous theoretical studies have been conducted dating back to the classical work of Maxwell (1881). The Maxwell model for thermal conductivity for solid-liquid mixtures of relatively large particles (micro-/minisize) is good for low solid concentrations. The effective thermal conductivity, $\mathrm{k}_{\mathrm{eff}}$, is given by

$\mathrm{k}_{\mathrm{eff}}=\frac{\mathrm{k}_{\mathrm{p}}+2 \mathrm{k}_{\mathrm{b}}+2\left(\mathrm{k}_{\mathrm{p}}-\mathrm{k}_{\mathrm{b}}\right) \phi}{\mathrm{k}_{\mathrm{p}}+2 \mathrm{k}_{\mathrm{b}}-\left(\mathrm{k}_{\mathrm{p}}-\mathrm{k}_{\mathrm{b}}\right) \phi} \mathrm{k}_{\mathrm{b}}$

where $\mathrm{k}_{\mathrm{p}}$ is the thermal conductivity of the particle, $\mathrm{k}_{\mathrm{b}}$ is the thermal conductivity of the base fluid and $\phi$ is the particle volume fraction in the suspension. Maxwell's formula shows that the effective thermal conductivity of nanofluids relies on the thermal conductivity of the spherical particle, the base fluid and the volume fraction of the solid particles.

Bruggeman (1935) proposed a model to analyze the interactions among randomly distributed particles. For a binary mixture of homogeneous spherical inclusions, the Bruggeman model gives

$$
\phi\left(\frac{\mathrm{k}_{\mathrm{p}}-\mathrm{k}_{\mathrm{eff}}}{\mathrm{k}_{\mathrm{p}}+2 \mathrm{k}_{\mathrm{eff}}}\right)+(1-\phi)\left(\frac{\mathrm{k}_{\mathrm{b}}-\mathrm{k}_{\mathrm{eff}}}{\mathrm{k}_{\mathrm{b}}+2 \mathrm{k}_{\mathrm{eff}}}\right)=0
$$

This model can be applied to spherical particles with no limitations on the concentration of inclusions. For low solid concentrations, the Bruggeman model results in almost the same results as the Maxwell model. When the particle concentration is sufficiently high, the Maxwell model fails to provide a good match with the experimental results. However, the Bruggeman model agrees quite well with the experimental data (Choi, 1995).

Hamilton and Crosser (1962) proposed a model for liquid-solid mixtures of non-spherical particles. They introduced a shape factor, $n$, to account for the effect of the shape of the particles. The thermal conductivity, in which the ratio of conductivity of the solid and fluid phases is larger than 100 $\left(\mathrm{k}_{\mathrm{p}} / \mathrm{k}_{\mathrm{b}}>100\right)$, can be expressed as follows: $\mathrm{k}_{\mathrm{eff}}=\frac{\mathrm{k}_{\mathrm{p}}+(\mathrm{n}-1) \mathrm{k}_{\mathrm{b}}-(\mathrm{n}-1)\left(\mathrm{k}_{\mathrm{b}}-\mathrm{k}_{\mathrm{p}}\right) \phi}{\mathrm{k}_{\mathrm{p}}+(\mathrm{n}-1) \mathrm{k}_{\mathrm{b}}+\left(\mathrm{k}_{\mathrm{b}}-\mathrm{k}_{\mathrm{p}}\right) \phi} \mathrm{k}_{\mathrm{b}}$

where $\mathrm{n}$ is the empirical shape factor given by $\mathrm{n}=3 / \psi$, and $\psi$ is the particle sphericity, defined as the ratio of the surface area of a sphere with volume equal to that of the particle, to the surface area of the particle. Comparison between Eq. (7) and Eq. (5) reveals that Maxwell's model is a special case of Hamilton and Crosser's model for sphericity equal to one.

As discussed earlier, the classical models are derived from continuum formulations and include only the particle shape and volume fraction as variables and assumed diffusive heat transport in both liquid and solid phases. The large enhancement of the effective thermal conductivity in nanofluids defies Maxwell's theory (Maxwell, 1881) as well as its modification by Hamilton and Crosser (1962). Some important mechanisms in nanofluids appear to be neglected in these models. Keblinski et al. (2002) investigated the possible factors of enhancing thermal conductivity in nanofluids such as the size, the clustering of particles, and the nano-layer between the nanoparticles and base fluids. Based on the traditional models, many later theoretical works have been proposed to address such effects, especially the interfacial characteristics.

$\mathrm{Yu}$ and Choi (2003) proposed a modified Maxwell model to account for the effect of the nanolayer by replacing the thermal conductivity of solid particles $\mathrm{k}_{\mathrm{p}}$ in Eq. (5) with the modified thermal conductivity of particles $\mathrm{k}_{\mathrm{pe}}$, which is based on the so-called effective medium theory (Schwartz et al., 1995):

$\mathrm{k}_{\mathrm{pe}}=\frac{\left[2(1-\gamma)+(1+\beta)^{3}(1+2 \gamma) \gamma\right]}{-(1-\gamma)+(1+\beta)^{3}(1+2 \gamma)} \mathrm{k}_{\mathrm{p}}$

where $\gamma=\mathrm{k}_{\text {layer }} / \mathrm{k}_{\mathrm{p}}$ is the ratio of nano-layer thermal conductivity to particle thermal conductivity and $\beta=h / r$ is the ratio of the nano-layer thickness to the original particle radius. Hence, the Maxwell equation (Eq. (5)) can be re-cast as follows:

$\mathrm{k}_{\mathrm{eff}}=\frac{\mathrm{k}_{\mathrm{pe}}+2 \mathrm{k}_{\mathrm{b}}+2\left(\mathrm{k}_{\mathrm{pe}}-\mathrm{k}_{\mathrm{b}}\right)(1-\beta)^{3} \phi}{\mathrm{k}_{\mathrm{pe}}+2 \mathrm{k}_{\mathrm{b}}-\left(\mathrm{k}_{\mathrm{pe}}-\mathrm{k}_{\mathrm{b}}\right)(1+\beta)^{3} \phi} \mathrm{k}_{\mathrm{b}}$ 
The new model including the nano-layer can predict the presence of very thin nano-layers having a thickness less than $10 \mathrm{~nm}$. It also indicates that the addition of smaller $(<10 \mathrm{~nm})$ particles could be better than increasing solid volume fraction with respect to the improvement of thermal conductivity.

$\mathrm{Yu}$ and Choi (2004) proposed a modified Hamilton-Crosser model to include the particleliquid interfacial layer for non-spherical particles. The effective thermal conductivity was expressed as

$\mathrm{k}_{\text {eff }}=\left(1+\frac{\mathrm{n} \phi_{\text {eff }} \mathrm{A}}{1-\phi_{\text {eff }} \mathrm{A}}\right) \mathrm{k}_{\mathrm{b}}$

where

A is defined by $\mathrm{A}=\frac{1}{3} \sum_{\mathrm{j}=\mathrm{a}, \mathrm{b}, \mathrm{c}}\left(\mathrm{k}_{\mathrm{pj}}-\mathrm{k}_{\mathrm{b}}\right) /\left[\mathrm{k}_{\mathrm{pj}}+(\mathrm{n}-1) \mathrm{k}_{\mathrm{b}}\right]$ and $\phi_{\text {eff }}=\phi \sqrt{\left(\mathrm{a}^{2}+\mathrm{t}\right)\left(\mathrm{b}^{2}+\mathrm{t}\right)\left(\mathrm{c}^{2}+\mathrm{t}\right)} / \sqrt{\mathrm{abc}}$ is the equivalent volume concentration of complex ellipsoids, which is an imaged structure of elliptical particles $(\mathrm{a}>\mathrm{b}>\mathrm{c})$ with surrounding nano-layers. With a general empirical shape factor $n\left(n=3 \Psi^{-\alpha}\right.$, here $\alpha$ is an empirical parameter and $\Psi$ is the particle sphericity), this modified $\mathrm{HC}$ model can predict the thermal conductivity of carbon nanotubein-oil nanofluids reasonably well. However, it fails to predict the nonlinear behavior of the effective thermal conductivity of general oxide and metalbased nanofluids.

Xue (2003) developed a model for the effective thermal conductivity of nanofluids. His model is based on the average polarization theory and includes the effect of the interface between the solid particles and the base fluid. His formula for the effective thermal conductivity is

$$
\begin{aligned}
& 9\left(1-\frac{\phi}{\lambda}\right) \frac{\mathrm{k}_{\text {eff }}-\mathrm{k}_{\mathrm{b}}}{2 \mathrm{k}_{\text {eff }}+\mathrm{k}_{\mathrm{b}}}+\frac{\phi}{\lambda} \\
& {\left[\begin{array}{c}
\frac{\mathrm{k}_{\mathrm{eff}}-\mathrm{k}_{\mathrm{c}, \mathrm{x}}}{\mathrm{k}_{\mathrm{eff}}+\mathrm{B}_{2, \mathrm{x}}\left(\mathrm{k}_{\mathrm{c}, \mathrm{x}}-\mathrm{k}_{\mathrm{eff}}\right)}+ \\
4 \frac{\mathrm{k}_{\text {eff }}-\mathrm{k}_{\mathrm{c}, \mathrm{y}}}{2 \mathrm{k}_{\mathrm{eff}}+\left(1-\mathrm{B}_{2, \mathrm{x}}\right)\left(\mathrm{k}_{\mathrm{c}, \mathrm{y}}-\mathrm{k}_{\text {eff }}\right)}
\end{array}\right]=0}
\end{aligned}
$$

where $\lambda=a b c /[(a+t)(b+t)(c+t)]$ with half-radii $(a, b, c)$ of the assumed elliptical complex nanoparticles, which consist of nanoparticles and interfacial shells between particles and the base fluids. $k_{c, j}$ is the effective dielectric constant and $\mathrm{B}_{2, \mathrm{x}}$ is the depolarization factor along the $\mathrm{x}$ symmetrical axis, which is derived from the average polarization theory. A test of this formula (Kim et al., 2004) reveals that it is not as accurate as Xue claimed since he used incorrect values of the parameters such as the depolarization factor. Xue and $\mathrm{Xu}$ (2005) obtained an equation for the effective thermal conductivity according to Bruggeman's model (Bruggeman, 1935). Their model takes into account the effect of interfacial shells by replacing the thermal conductivity of nanoparticles with the assumed thermal conductivity of the so-called "complex nanoparticles", which included the interfacial shells between the nanoparticles and the base fluids.

$$
\begin{aligned}
& \left(1-\frac{\phi}{\alpha}\right) \frac{\mathrm{k}_{\text {eff }}-\mathrm{k}_{\mathrm{b}}}{2 \mathrm{k}_{\text {eff }}+\mathrm{k}_{\mathrm{b}}}+\frac{\phi}{\alpha} \\
& \frac{\left(\mathrm{k}_{\text {eff }}-\mathrm{k}_{2}\right)\left(2 \mathrm{k}_{2}+\mathrm{k}_{1}\right)-\alpha\left(\mathrm{k}_{1}-\mathrm{k}_{2}\right)\left(2 \mathrm{k}_{2}+\mathrm{k}_{\text {eff }}\right)}{\left(2 \mathrm{k}_{\mathrm{eff}}+\mathrm{k}_{2}\right)\left(2 \mathrm{k}_{2}+\mathrm{k}_{1}\right)+2 \alpha\left(\mathrm{k}_{1}-\mathrm{k}_{2}\right)\left(\mathrm{k}_{2}-\mathrm{k}_{\mathrm{eff}}\right)}=0
\end{aligned}
$$

where $\alpha$ is the volume ratio of spherical nanoparticle and complex nanoparticle, and $\mathrm{k}_{1}$ and $\mathrm{k}_{2}$ are the thermal conductivity of the nanoparticle and interfacial shell, respectively. The modified model is in good agreement with the experimental data on the effective thermal conductivity of $\mathrm{CuO} /$ water and $\mathrm{CuO} / \mathrm{EG}$ nanofluids (Lee et al., 1999).

Xie et al. (2005) considered the interfacial nanolayer with linear thermal conductivity distribution and proposed an effective thermal conductivity model to account for the effects of nano-layer thickness, nanoparticle size, volume fraction, and thermal conductivities of fluid, nanoparticles, and nano-layer. Their formula is

$\mathrm{k}_{\mathrm{eff}}=\left(1+3 \Theta \phi_{\mathrm{T}}+\frac{3 \Theta^{2} \phi_{\mathrm{T}}^{2}}{1-\Theta \phi_{\mathrm{T}}}\right) \mathrm{k}_{\mathrm{b}}$

with

$\Theta=\left\{\beta_{\mathrm{lb}}\left[(1+\gamma)^{3}-\beta_{\mathrm{pl}} / \beta_{\mathrm{bl}}\right]\right\} /\left[(1+\gamma)^{3}+2 \beta_{\mathrm{lb}} \beta_{\mathrm{pl}}\right]$,

where

$\beta_{\mathrm{lb}}=\left(\mathrm{k}_{1}-\mathrm{k}_{\mathrm{b}}\right) /\left(\mathrm{k}_{1}+2 \mathrm{k}_{\mathrm{b}}\right)$, 
$\beta_{\mathrm{pl}}=\left(\mathrm{k}_{\mathrm{p}}-\mathrm{k}_{1}\right) /\left(\mathrm{k}_{\mathrm{p}}+2 \mathrm{k}_{1}\right)$,

$\beta_{\mathrm{bl}}=\left(\mathrm{k}_{\mathrm{b}}-\mathrm{k}_{1}\right) /\left(\mathrm{k}_{\mathrm{b}}+2 \mathrm{k}_{1}\right)$

and $\gamma=\delta / r_{p}$ is the thickness ratio of nano-layer and nanoparticle. $\phi_{\mathrm{T}}$ is the modified total volume fraction of the original nanoparticle and nano-layer, $\phi_{\mathrm{T}}=\phi(1+\gamma)^{3}$. They claimed that the calculated values agreed well with some available experimental data.

For metallic particles, Patel et al. (2003) found 9\% enhancement of thermal conductivity even at extremely low concentrations such as $0.00026 \%$. (Note that if not mentioned in the text, the concentration is in volume fraction.) The previous formulas fail to predict such strange phenomena. The Brownian motion of nanoparticles at the molecular and nano-scale levels may be a key mechanism governing the thermal behavior of nanofluids. Also, in recent experiments (Das et al., 2003b), we find that the thermal conductivity of nanofluids depends strongly on temperature. Hence, this important fact should be considered in theoretical models.

Xuan et al. (2003) considered the random motion of suspended nanoparticles (Brownian motion) based on the Maxwell model and proposed a modified formula for the effective thermal conductivity as follows:

$\mathrm{k}_{\mathrm{eff}}=\frac{\mathrm{k}_{\mathrm{p}}+2 \mathrm{k}_{\mathrm{b}}-2\left(\mathrm{k}_{\mathrm{b}}-\mathrm{k}_{\mathrm{p}}\right) \phi}{\mathrm{k}_{\mathrm{p}}+2 \mathrm{k}_{\mathrm{b}}+\left(\mathrm{k}_{\mathrm{b}}-\mathrm{k}_{\mathrm{p}}\right) \phi} \mathrm{k}_{\mathrm{b}}+\frac{\rho_{\mathrm{p}} \phi \mathrm{c}_{\mathrm{p}}}{2} \sqrt{\frac{\mathrm{k}_{\mathrm{B}} \mathrm{T}}{3 \pi \mathrm{r}_{\mathrm{c}} \mu}}$

where the Boltzmann constant is $\mathrm{k}_{\mathrm{B}}=1.381 \times 10^{-23} \mathrm{~J} / \mathrm{K} ; \mathrm{r}_{\mathrm{c}}$ is the apparent radius of clusters and depends on the fractal dimension of the cluster structure. Although this model incorporates the effect of temperature on the conductivity enhancement, the dependence is too weak $\left(\propto \mathrm{T}^{1 / 2}\right)$ and not in agreement with the experimental data of Das et al. (2003b).

Based on the fractal theory (Mandelbrot, 1982), which can describe well the disorder and stochastic process of clustering and polarization of nanoparticles within the mesoscale limit, a fractal model for predicting the effective thermal conductivity of nanofluid was proposed by Wang et al. (2003), who developed a fractal model based on the multi-component Maxwell model by substituting the effective thermal conductivity of the particle clusters, $\mathrm{k}_{\mathrm{cl}}(\mathrm{r})$, and the radius distribution function, $\mathrm{n}(\mathrm{r})$, as follows:

$\mathrm{k}_{\text {eff }}=\frac{(1-\phi)+3 \phi \int_{0}^{\infty} \mathrm{k}_{\mathrm{cl}}(\mathrm{r}) \mathrm{n}(\mathrm{r}) /\left[\mathrm{k}_{\mathrm{cl}}(\mathrm{r})+2 \mathrm{k}_{\mathrm{b}}\right] \mathrm{dr}}{(1-\phi)+3 \phi \int_{0}^{\infty} \mathrm{k}_{\mathrm{b}}(\mathrm{r}) \mathrm{n}(\mathrm{r}) /\left[\mathrm{k}_{\mathrm{cl}}(\mathrm{r})+2 \mathrm{k}_{\mathrm{b}}\right] \mathrm{dr}} \mathrm{k}_{\mathrm{b}}$

This model fit successfully the experimental data for a $50 \mathrm{~nm} \mathrm{CuO} \mathrm{particle} \mathrm{suspension} \mathrm{in} \mathrm{deionized}$ water with $\phi<0.5 \%$.

Kumar et al. (2004) proposed a comprehensive model to account for the large enhancement of thermal conductivity in nanofluids and its strong temperature dependence, which was deduced from the Stokes-Einstein formula. The thermal conductivity enhancement taking account of the Brownian motion of particles can be expressed as:

$\mathrm{k}_{\text {eff }}=\mathrm{k}_{\mathrm{b}}+\mathrm{c} \frac{2 \mathrm{k}_{\mathrm{B}} \mathrm{T}}{\left(\pi v \mathrm{~d}_{\mathrm{p}}^{2}\right)} \frac{\phi \mathrm{r}_{\mathrm{b}}}{\mathrm{k}_{\mathrm{b}}(1-\phi) \mathrm{r}_{\mathrm{p}}} \mathrm{k}_{\mathrm{b}}$

where $\mathrm{c}$ is a constant, $\nu$ is the dynamic viscosity of the base fluid, and $d_{p}$ is the diameter of the particles. However, the validity of the model has got to be established; it may not be suitable for high concentrations of particles.

Bhattacharya et al. (2004) developed a technique to compute the effective thermal conductivity of a nanofluid using Brownian motion simulation. They combined the liquid conductivity and particle conductivity as follows

$\mathrm{k}_{\mathrm{eff}}=\phi \mathrm{k}_{\mathrm{p}}+(1-\phi) \mathrm{k}_{\mathrm{b}}$

where $\mathrm{k}_{\mathrm{p}}$ is replaced by the effective contribution of the particles towards the overall thermal conductivity of the system, $k_{p}=\frac{1}{k_{B} T^{2} V} \sum_{j=0}^{n}\langle Q(0) Q(j \Delta t)\rangle \Delta t$. The model showed a good agreement with the thermal conductivity of nanofluids.

Jang and Choi (2004b) devised a theoretical model that involves four modes such as collision between base fluid molecules $\left(\mathrm{k}_{\mathrm{b}}(1-\phi)\right)$, thermal diffusion in nanoparticles in fluids $\mathrm{k}_{\mathrm{p}} \phi$, collision between nanoparticles due to Brownian motion (neglected), and thermal interaction of dynamic or "dancing" nanoparticles with the base fluid molecules $\left(f h \delta_{T}\right)$. The resulting expression for the effective thermal conductivity of nanofluids is 


$$
\mathrm{k}_{\text {eff }}=\mathrm{k}_{\mathrm{b}}(1-\phi)+\mathrm{k}_{\mathrm{p}} \phi+3 \mathrm{C} \frac{\mathrm{d}_{\mathrm{b}}}{\mathrm{d}_{\mathrm{p}}} \mathrm{k}_{\mathrm{b}} \operatorname{Re}_{\mathrm{d}_{\mathrm{p}}}^{2} \operatorname{Pr} \phi
$$

where $\mathrm{h} \sim \frac{\mathrm{k}_{\mathrm{b}}}{\mathrm{d}_{\mathrm{p}}} \operatorname{Re}_{\mathrm{d}_{\mathrm{p}}}^{2} \operatorname{Pr}^{2}$ and $\delta \sim 3 \mathrm{~d}_{\mathrm{p}}$ represent the heat transfer coefficient for the flow past nanoparticles and the thickness of the thermal boundary layer, respectively. The advantage of the model is to include the effects of concentration, temperature, and particle size. However, the Brownian effect was neglected, which may not be suitable since the high temperature-dependent properties may be caused by the Brownian motion.

On the other hand, Prasher (Putnam et al., 2006) proposed that convection caused by Brownian motion of the nanoparticles is primarily responsible for the enhancement of the effective thermal conductivity of nanofluids. By introducing the general correlation for heat transfer coefficient $h$, he modified the Maxwell model by including the convection of the liquid near the particles due to Brownian movement:

$\mathrm{k}_{\mathrm{eff}}=\left(1+\mathrm{ARe}^{\mathrm{m}} \operatorname{Pr}^{0.333} \phi\right)\left[\frac{\mathrm{k}_{\mathrm{p}}+2 \mathrm{k}_{\mathrm{b}}+2\left(\mathrm{k}_{\mathrm{p}}-\mathrm{k}_{\mathrm{b}}\right) \phi}{\mathrm{k}_{\mathrm{p}}+2 \mathrm{k}_{\mathrm{b}}-\left(\mathrm{k}_{\mathrm{p}}-\mathrm{k}_{\mathrm{b}}\right) \phi}\right] \mathrm{k}_{\mathrm{b}}$

where $\mathrm{h}=\mathrm{k}_{\mathrm{b}} / \mathrm{a}\left(1+\mathrm{ARe}^{\mathrm{m}} \operatorname{Pr}^{0.333} \phi\right)$ and $\mathrm{A}$ and $\mathrm{m}$ are constants. The Reynolds number can be written as:

$\operatorname{Re}=\frac{1}{v} \sqrt{\frac{18 \mathrm{k}_{\mathrm{b}} \mathrm{T}}{\pi \rho_{\mathrm{p}} \mathrm{d}_{\mathrm{p}}}}$

Recently, Koo and Kleinstreuer (2004, 2005b) developed a new model for nanofluids, which includes the effects of particle size, particle volume fraction and temperature dependence as well as properties of the base fluid and the particle subject to Brownian motion. The resulting formula is

$$
\begin{aligned}
& \mathrm{k}_{\text {eff }}=\frac{\mathrm{k}_{\mathrm{p}}+2 \mathrm{k}_{\mathrm{b}}+2\left(\mathrm{k}_{\mathrm{p}}-\mathrm{k}_{\mathrm{b}}\right) \phi}{\mathrm{k}_{\mathrm{p}}+2 \mathrm{k}_{\mathrm{b}}-\left(\mathrm{k}_{\mathrm{p}}-\mathrm{k}_{\mathrm{b}}\right) \phi} \mathrm{k}_{\mathrm{b}}+ \\
& 5 \times 10^{4} \beta \phi \rho_{\mathrm{p}} \mathrm{c}_{\mathrm{p}} \sqrt{\frac{\mathrm{k}_{\mathrm{B}} \mathrm{T}}{\rho_{\mathrm{p}} \mathrm{D}}} \mathrm{f}(\mathrm{T}, \phi)
\end{aligned}
$$

Note that the first part of Eq. (20) is obtained directly from the Maxwell model while the second part accounts for Brownian motion, which causes the temperature dependence of the effective thermal conductivity. The function $\mathrm{f}(\mathrm{T}, \phi)$ can be assumed to vary continuously with the particle volume fraction, $\mathrm{f}(\mathrm{T}, \phi)=(-6.04 \phi+0.4705) \mathrm{T}+(1722.3 \phi-134.63)$ while $\beta$ is related to particle motion. Based on the investigation of pressure gradients, temperature profiles and Nusselt numbers, Koo and Kleinstreuer (2005b) also claimed that addition of 1$4 \% \mathrm{CuO}$ nanoparticles and high-Prandtl number base fluid such as ethylene glycol and oils could significantly increase the heat transfer performance of micro-heat sinks.

Considering the fact that carbon nanotubes possess a large aspect ratio, their thermal conductivity is more difficult to predict. Nan et al. (2003) generalized the Maxwell-Garnett approximation and derived a simple formula $\mathrm{k}_{\text {eff }}=1+\phi \mathrm{k}_{\mathrm{p}} / 3 \mathrm{k}_{\mathrm{b}}$ to predict the effective thermal conductivity of carbon-nanotube-based composites. The results within Nan's model (Nan et al., 2003) agree well with the experimental observations (Choi et al., 2001). However, this model does not consider the thermal resistance across the carbon nanotube-fluid interface. Later, Nan et al. (2004) modified their model and tried to describe the effect of the interface thermal resistance. However, the model still cannot explain the nonlinear phenomena of the effective thermal conductivity of nanotube suspensions with nanotube volume fractions. Recently, to account for the geometric and physical anisotropy simultaneously, Gao and Zhou (2005) proposed a differential effective medium theory based on Bruggeman's model (Bruggeman, 1935) to predict the effective thermal conductivity of nanofluids. Although their model involves the effect of aspect ratio of the nanotube, the size effect and temperature dependence were not included. From the results, the prediction of the thermal conductivity of nanotube-based suspensions is not good.

For carbon nanofibers, Yamada and Ota (1980) proposed the unit-cell model for the effective thermal conductivity of mixture, which is

$\mathrm{k}_{\mathrm{eff}}=\frac{\mathrm{k}_{\mathrm{p}} / \mathrm{k}_{\mathrm{b}}+\mathrm{K}-\mathrm{K} \phi\left(1-\mathrm{k}_{\mathrm{p}} / \mathrm{k}_{\mathrm{b}}\right)}{\mathrm{k}_{\mathrm{p}} / \mathrm{k}_{\mathrm{b}}+\mathrm{K}+\phi\left(1-\mathrm{k}_{\mathrm{p}} / \mathrm{k}_{\mathrm{b}}\right)} \mathrm{k}_{\mathrm{b}}$

where, $\mathrm{K}$ is the shape factor and $\mathrm{K}=2 \phi^{0.2}\left(1_{\mathrm{p}} / \mathrm{d}_{\mathrm{p}}\right)$ for the cylindrical particles, and $\mathrm{l}_{\mathrm{p}}$ and $\mathrm{d}_{\mathrm{p}}$ are the length and diameter of the cylindrical particle. 
Recently, Xue (2005) proposed a Maxwell theory based model of the effective thermal conductivity of carbon nanotube (CNT) nanofluids to include the effect of large axial ratio and the space distribution of the CNTs. As compared with the existing experimental data (Choi et al., 2001), the proposed model provided reasonable agreement with adjusted thermal conductivity of CNTs. With the assumed distribution function $\mathrm{P}\left(\mathrm{B}_{\mathrm{j}}\right)=2$, the corresponding expression for the effective thermal conductivity of CNT-based nanofluids is

$$
\mathrm{k}_{\mathrm{eff}}=\mathrm{k}_{\mathrm{b}} \frac{1-\phi+2 \phi \frac{\mathrm{k}_{\mathrm{p}}}{\mathrm{k}_{\mathrm{p}}-\mathrm{k}_{\mathrm{b}}} \ln \frac{\mathrm{k}_{\mathrm{p}}+\mathrm{k}_{\mathrm{b}}}{2 \mathrm{k}_{\mathrm{b}}}}{1-\phi+2 \phi \frac{\mathrm{k}_{\mathrm{b}}}{\mathrm{k}_{\mathrm{p}}-\mathrm{k}_{\mathrm{b}}} \ln \frac{\mathrm{k}_{\mathrm{p}}+\mathrm{k}_{\mathrm{b}}}{2 \mathrm{k}_{\mathrm{b}}}}
$$

Xue (2006) also presented a model for the effective thermal conductivity of carbon nanotube composites by incorporating the interface thermal resistance with an average polarization theory. The proposed model includes the effects of carbon nanotube length, diameter, concentration, interface thermal resistance, and the thermal conductivities of nanotube and base fluid on the thermal conductivity of the nanofluid simultaneously.

$$
\begin{aligned}
& 9(1-\phi) \frac{\mathrm{k}_{\text {eff }}-\mathrm{k}_{\mathrm{b}}}{2 \mathrm{k}_{\text {eff }}+\mathrm{k}_{\mathrm{b}}}+ \\
& \phi\left[\frac{\mathrm{k}_{\text {eff }}-\mathrm{k}_{33}^{\mathrm{c}}}{\mathrm{k}_{\text {eff }}+0.14 \frac{\mathrm{d}}{\mathrm{L}}\left(\mathrm{k}_{33}^{\mathrm{c}}-\mathrm{k}_{\text {eff }}\right)}+4 \frac{\mathrm{k}_{\text {eff }}-\mathrm{k}_{11}^{\mathrm{c}}}{2 \mathrm{k}_{\text {eff }}+\frac{1}{2}\left(\mathrm{k}_{11}^{\mathrm{c}}-\mathrm{k}_{\text {eff }}\right)}\right]=0
\end{aligned}
$$

where $\mathrm{k}_{11}^{\mathrm{c}}$ and $\mathrm{k}_{33}^{\mathrm{c}}$ are the transverse and longitudinal equivalent thermal conductivities of the composite unit cell of a nanotube with length $\mathrm{L}$ and diameter $\mathrm{d}$. The model predicts that the nanotube diameter has a negligible effect on the thermal conductivity enhancement of the nanotube nanofluids. It seems that the model agrees well with the data of Xie et al. (2003).

Fig. 2 shows a comparison between selected discussed theoretical models and experimental data on thermal conductivity of $\mathrm{Al}_{2} \mathrm{O}_{3}$ /water nanofluids. To obtain a deeper understanding of the effective thermal conductivity of nanofluids, some important facts must be taken to account in future studies. Such facts include the effect of the size and shape of the nanoparticles, the interfacial contact resistance between nanoparticles and base fluids, the temperature dependence or the effect of Brownian motion, and the effect of clustering of particles.

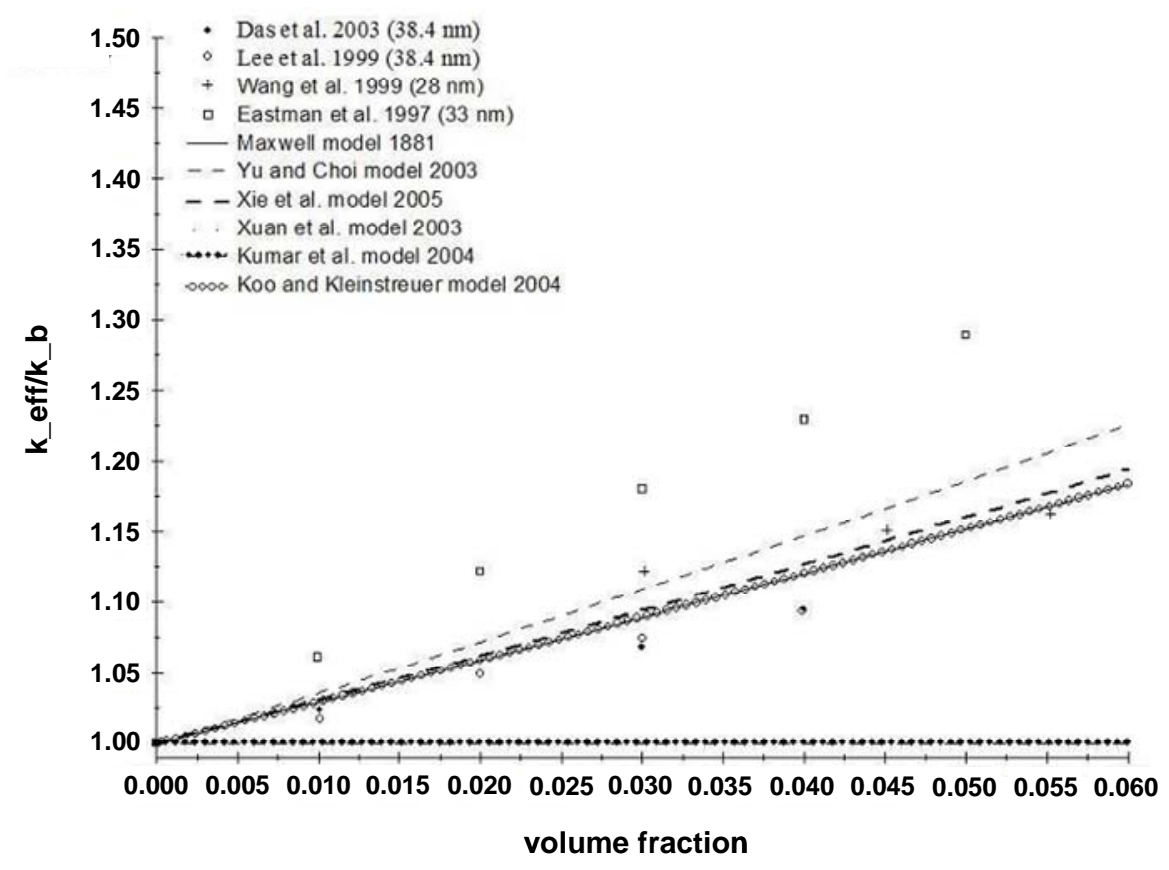

Figure 2: Comparison between selected theoretical models and experimental data for thermal conductivity for $\mathrm{Al}_{2} \mathrm{O}_{3}$ /water nanofluids. 
622

\section{Viscosity}

Einstein (1956) was the first to calculate the effective viscosity of a suspension of spherical solids using the phenomenological hydrodynamic equations. By assuming that the disturbance of the flow pattern of the matrix base fluid caused by a given particle does not overlap with the disturbance of flow caused by the presence of a second suspended particle, he derived the following equations

$\mu_{\text {eff }}=\left(1+2.5 \phi_{\mathrm{p}}\right) \mu_{\mathrm{b}}$

Even since Einstein's initial work, researchers have made progress in extending the Einstein theory in three major areas.

1. To extend the Einstein equation to higher particle volume concentrations by including particle-particle interactions. The theoretical equation can be expressed as: $\mu_{\text {eff }}=\left(1+c_{1} \phi_{\mathrm{p}}+\mathrm{c}_{2} \phi_{\mathrm{p}}^{2}+\mathrm{c}_{3} \phi_{\mathrm{p}}^{3}+\cdots\right) \mu_{\mathrm{b}}$.

2. To take into account the fact that the effective viscosity of a mixture becomes infinite at the maximum particle volume concentration $\phi_{\mathrm{p} \max } .3$.
This theoretical equation usually has the term $\left[1-\left(\phi_{\mathrm{p}} / \phi_{\mathrm{p} \text { max }}\right)\right]^{\alpha}$ in the denominator, which can be expressed in a form similar to (1).

To include the effect of non-spherical particle concentrations. Some of these equations are included in Table 2.

Experimental data for the effective viscosity of nanofluids are limited to certain nanofluids. The ranges of the parameters (the particle volume concentration, temperature, etc.) are also limited. Still, the experimental data show the trend that the effective viscosities of nanofluids are higher than the existing theoretical predictions. In an attempt to rectify this situation, researchers proposed equations applied to specific applications, e.g., $\mathrm{Al}_{2} \mathrm{O}_{3}$ in water (Maiga et al., 2004a), $\mathrm{Al}_{2} \mathrm{O}_{3}$ in ethylene glycol (Maiga et al., 2004a), $\mathrm{TiO}_{2}$ in water (Tseng and Lin, 2003), and $\mathrm{CuO}$ in water with temperature change (Kulkarni et al., 2006). The problem with these equations is that they do not reduce to the Einstein equation at very low particle volume concentrations and, hence, lack a sound physical basis.

Table 2: Models for effective viscosity

\begin{tabular}{|l|l|}
\hline Investigator & Equation \\
\hline Einstein (1906) & $\mu_{\text {eff }}=\left(1+2.5 \phi_{\mathrm{p}}\right) \mu_{\mathrm{b}}$ \\
\hline Simha (1940) & $\mu_{\text {eff }}=\left\{1+\frac{1}{15}\left[1+\frac{(\mathrm{a} / \mathrm{c})^{2}}{\ln (2 \mathrm{a} / \mathrm{c})-1.5}+\frac{3(\mathrm{a} / \mathrm{c})^{2}}{\ln (2 \mathrm{a} / \mathrm{c})-0.5}\right] \phi_{\mathrm{p}}\right\} \mu_{\mathrm{b}}$ \\
\hline Simha (1940) & $\mu_{\text {eff }}=\left[1+\frac{16}{15} \frac{(\mathrm{a} / \mathrm{c})}{\arctan (\mathrm{a} / \mathrm{c})} \phi_{\mathrm{p}}\right] \mu_{\mathrm{b}}$ \\
\hline Eilers (1941) & $\mu_{\text {eff }}=\left[1+\frac{1.25}{1-\left(\phi_{\mathrm{p}} / \phi_{\mathrm{p} \max }\right)} \phi_{\mathrm{p}}\right] \mu_{\mathrm{b}}=$ \\
\hline De Bruijn (1942) & $\left\{1+2.5 \phi_{\mathrm{p}}+\left[1.5625+\left(2.5 / \phi_{\mathrm{p} \text { max }}\right)\right] \phi_{\mathrm{p}}^{2}+\cdots\right\} \mu_{\mathrm{b}}$ \\
\hline Kuhn and Kuhn (1945) & $\mu_{\text {eff }}=\frac{1}{1.25 \phi_{\mathrm{p}}+1.552 \phi_{\mathrm{p}}^{2}} \mu_{\mathrm{b}}=\left(1+2.5 \phi_{\mathrm{p}}+4.698 \phi_{\mathrm{p}}^{2}+\cdots\right) \mu_{\mathrm{b}}$ \\
\hline Vand (1948) & $\mu_{\text {eff }}=\left\{1+\frac{1}{15}\left[24+\frac{(\mathrm{a} / \mathrm{c})^{2}}{\ln (2 \mathrm{a} / \mathrm{c})-1.5}+\frac{3(\mathrm{a} / \mathrm{c})^{2}}{\ln (2 \mathrm{a} / \mathrm{c})-0.5}\right] \phi_{\mathrm{p}}\right\} \mu_{\mathrm{b}}$ \\
\hline Vand (1948) & $\mu_{\text {eff }}=\left(1+2.5 \phi_{\mathrm{p}}+7.349 \phi_{\mathrm{p}}^{2}+\cdots\right) \mu_{\mathrm{b}}$ \\
\hline Robinson (1949) & $\mu_{\text {eff }}=\mathrm{e}^{2.5 \phi_{\mathrm{p}}} \mu_{\mathrm{b}}=\left(1+2.5 \phi_{\mathrm{p}}+3.125 \phi_{\mathrm{p}}^{2}+\cdots\right) \mu_{\mathrm{b}}$ \\
\hline Saito (1950) & $\mu_{\text {eff }}=\left(1+\frac{\mathrm{c}_{\mathrm{p}} \phi_{\mathrm{p}}}{1-\mathrm{s}_{\mathrm{r}} \phi_{\mathrm{p}}}\right) \mu_{\mathrm{b}}=\left(1+\mathrm{c}_{\mathrm{p}} \phi_{\mathrm{p}}+\mathrm{c}_{\mathrm{p}} \mathrm{s}_{\mathrm{r}} \phi_{\mathrm{p}}^{2}+\cdots\right) \mu_{\mathrm{b}}$ \\
\hline
\end{tabular}




\section{Continuation Table 2}

Table 2: Models for effective viscosity

\begin{tabular}{|c|c|}
\hline Investigator & Equation \\
\hline Saito (1950) & $\mu_{\mathrm{eff}}=\left(1+\frac{2.5}{1-\phi_{\mathrm{p}}} \phi_{\mathrm{p}}\right) \mu_{\mathrm{b}}=\left(1+2.5 \phi_{\mathrm{p}}+2.5 \phi_{\mathrm{p}}^{2}+\cdots\right) \mu_{\mathrm{b}}$ \\
\hline Mooney (1951) & $\begin{array}{l}\mu_{\text {eff }}=\exp \left(2.5 \phi_{\mathrm{p}} /\left[1-\left(\phi_{\mathrm{p}} / \phi_{\mathrm{p} \max }\right)\right]\right) \mu_{\mathrm{b}}= \\
\left\{1+2.5 \phi_{\mathrm{p}}+\left[3.125+\left(2.5 / \phi_{\mathrm{p} \max }\right)\right] \phi_{\mathrm{p}}^{2}+\cdots\right\} \mu_{\mathrm{b}}\end{array}$ \\
\hline Brinkman (1952) & $\mu_{\text {eff }}=\frac{1}{\left(1-\phi_{\mathrm{p}}\right)^{2.5}} \mu_{\mathrm{b}}=\left(1+2.5 \phi_{\mathrm{p}}+4.375 \phi_{2}+\cdots\right) \mu_{\mathrm{b}}$ \\
\hline Simha (1952) & $\mu_{\mathrm{eff}}=\left\{1+2.5 \phi_{\mathrm{p}}+\left[125 /\left(64 \phi_{\mathrm{p} \max }\right)\right] \phi_{\mathrm{p}}^{2}+\cdots\right\} \mu_{\mathrm{b}}$ \\
\hline Eshelby (1957) & $\mu_{\text {eff }}=\left(1+\frac{15}{2} \frac{1-\sigma_{p}}{4-5 \sigma_{p}} \phi_{p}\right) \mu_{b}=\left(1+\frac{15}{7} \phi_{p}\right) \mu_{b}, \sigma_{p} \simeq 1 / 3$ \\
\hline Frankel and Acrivos (1967) & $\mu_{\text {eff }}=\frac{9}{8} \frac{\left(\phi_{\mathrm{p}} / \phi_{\mathrm{p} \max }\right)^{1 / 3}}{1-\left(\phi_{\mathrm{p}} / \phi_{\mathrm{p} \max }\right)^{1 / 3}} \mu_{\mathrm{b}}$ \\
\hline Krieger (1972) & $\begin{array}{l}\mu_{\mathrm{eff}}=\frac{1}{\left[1-\left(\phi_{\mathrm{p}} / \phi_{\mathrm{p} \max }\right)\right]^{1.82}} \mu_{\mathrm{b}}= \\
{\left[1+\left(1.82 / \phi_{\mathrm{p} \max }\right) \phi_{\mathrm{p}}+\left(2.5662 / \phi_{\mathrm{p} \max }^{2}\right) \phi_{\mathrm{p}}^{2}+\cdots\right] \mu_{\mathrm{b}}}\end{array}$ \\
\hline Lundgren (1972) & $\mu_{\mathrm{eff}}=\frac{1}{1-2.5 \phi_{\mathrm{p}}} \mu_{\mathrm{b}}=\left(1+2.5 \phi_{\mathrm{p}}+6.25 \phi_{\mathrm{p}}^{2}+\cdots\right) \mu_{\mathrm{b}}$ \\
\hline Batchelor (1977) & $\mu_{\mathrm{eff}}=\left(1+2.5 \phi_{\mathrm{p}}+6.2 \phi_{\mathrm{p}}^{2}\right) \mu_{\mathrm{b}}$ \\
\hline Graham (1981) & $\mu_{\text {eff }}=\left[1+2.5 \phi_{\mathrm{p}}+\frac{4.5}{\left.\left(\mathrm{~s}_{\mathrm{p}} / \mathrm{r}_{\mathrm{p}}\right)\left[2+\left(\mathrm{s}_{\mathrm{p}} / \mathrm{r}_{\mathrm{p}}\right)\right] 1+\left(\mathrm{s}_{\mathrm{p}} / \mathrm{r}_{\mathrm{p}}\right)\right]^{2}}\right] \mu_{\mathrm{b}}$ \\
\hline Phan-Thien and Graham (1991) & $\mu_{\mathrm{eff}}=\left\{1+\left(1.461+0.138 \frac{\mathrm{a}}{\mathrm{c}}\right) \frac{1-0.5\left(\phi_{\mathrm{p}} / \phi_{\mathrm{p} \max }\right)}{\left[1-\left(\phi_{\mathrm{p}} / \phi_{\mathrm{p} \max }\right)\right]^{2}}\right\} \mu_{\mathrm{b}}$ \\
\hline Liu and Masliyah (1996) & $\begin{array}{l}\mu_{\text {eff }}=\left\{\frac{1}{\left[1-\left(\phi_{\mathrm{p}} / \phi_{\mathrm{p} \max }\right)\right]^{2}}+\left[\mathrm{c}_{1}-\left(2 / \phi_{\mathrm{p} \max }\right)\right] \phi_{\mathrm{p}}+\left[\mathrm{c}_{2}-\left(6 / \phi_{\mathrm{p} \max }^{2}\right)\right] \phi_{\mathrm{p}}^{2}\right\} \mu_{\mathrm{b}} \\
=\left\{1+\mathrm{c}_{1} \phi_{\mathrm{p}}+\left[\mathrm{c}_{2}-\left(3 / \phi_{\mathrm{p} \max }^{2}\right)\right] \phi_{\mathrm{p}}^{2}+\cdots\right\} \mu_{\mathrm{b}}\end{array}$ \\
\hline Tseng and Lin (2003) & $\mu_{\mathrm{eff}}=13.47 \exp \left(35.98 \phi_{\mathrm{p}}\right) \mu_{\mathrm{b}}$ \\
\hline Maïga et al. (2004) & $\mu_{\mathrm{eff}}=\left(1+7.3 \phi_{\mathrm{p}}+123 \phi_{\mathrm{p}}^{2}\right) \mu_{\mathrm{b}}$ \\
\hline Maïga et al. (2004) & $\mu_{\text {eff }}=\left(1-0.19 \phi_{\mathrm{p}}+306 \phi_{\mathrm{p}}^{2}\right) \mu_{\mathrm{b}}$ \\
\hline Koo and Kleinstreuer (2005) & $\begin{array}{l}\mu_{\text {Brownian }}=5 \times 10^{4} \beta \rho_{\mathrm{b}} \phi_{\mathrm{p}} \sqrt{\frac{\mathrm{k}_{\mathrm{B}} \mathrm{T}}{2 \rho_{\mathrm{p}} \mathrm{r}_{\mathrm{p}}}\left[\left(-134.63+1722.3 \phi_{\mathrm{p}}\right)+\left(0.4705-6.04 \phi_{\mathrm{p}}\right) \mathrm{T}\right]} \\
\text { where the particle motion related empirical parameter } \\
\beta= \begin{cases}0.0137\left(100 \phi_{\mathrm{p}}\right)^{-0.8229} & \phi_{\mathrm{p}}<0.01 \\
0.0011\left(100 \phi_{\mathrm{p}}\right)^{-0.7272} & \phi_{\mathrm{p}}>0.01\end{cases} \end{array}$ \\
\hline Kulkarni et al. (2006) & $\ln \mu_{\text {eff }}=-\left(2.8751+53.548 \phi_{\mathrm{p}}-107.12 \phi_{\mathrm{p}}^{2}\right)+\left(1078.3+15857 \phi_{\mathrm{p}}+20587 \phi_{\mathrm{p}}^{2}\right)(1 / \mathrm{T})$ \\
\hline
\end{tabular}




\section{Heat Transfer Coefficient}

Since the heat transfer performance is a better indicator than the effective thermal conductivity for nanofluids used as coolants in transportation and other industries, the modeling of nanofluid heat transfer coefficients is gaining attention from researchers. However, it is still at an early stage, and the theoretical models for nanofluid heat transfer coefficients are quite limited. All the equations are modified from traditional equations such as the Dittus-Boelter equation (Dittus and Boelter, 1930) or the Gnielinski equation (Gnielinski, 1976) with empirical parameters added. Therefore, these equations are only valid for certain nanofluids over small parameter ranges. More experimental and theoretical studies are needed before general models can be developed and verified.

Recently, Polidori et al. (2007) investigated the natural convection heat transfer of Newtonian $\gamma \mathrm{Al}_{2} \mathrm{O}_{3}$ /water nanofluids in a laminar external boundary-layer using the integral formalism approach. Based on a macroscopic modeling and under the assumption of constant thermophysical nanofluid properties, it is shown that natural convection heat transfer is not solely characterized by the nanofluid effective thermal conductivity and that the sensitivity to the viscosity model used seems undeniable and plays a key role in the heat transfer behavior.

Mansour et al. (2007) investigated the effect of uncertainty in the physical properties of $\gamma \mathrm{Al}_{2} \mathrm{O}_{3}$ /water nanofluid on its thermohydraulic performance for both laminar and turbulent fully developed forced convection in a tube with uniform heat flux. Since the effects of certain nanofluid characteristics such as average particle size and spatial distribution of nanoparticles on these properties are not presently known precisely, it is quite difficult to conclude as to the presumed advantages of nanofluids over conventional heat transfer fluids. More experimental data regarding these effects are needed in order to assess the true potential of nanofluids.

Table 3: Models of effective heat transfer coefficient

\begin{tabular}{|c|c|c|}
\hline Investigator & Nanofluids & Correlation \\
\hline (Pak and Cho, 1998) & $\begin{array}{l}\mathrm{Al}_{2} \mathrm{O}_{3} \text {-water, } \mathrm{TiO}_{2} \text {-water, } \\
\text { turbulent }\end{array}$ & $\mathrm{Nu}=0.021 \operatorname{Re}^{0.8} \operatorname{Pr}^{0.5}$ \\
\hline (Das et al., 2003a) & $\mathrm{Al}_{2} \mathrm{O}_{3}$-water, pool boiling & $\begin{array}{l}\mathrm{Nu}=\mathrm{c} \mathrm{Re}{ }_{\mathrm{b}}^{\mathrm{m}} \operatorname{Pr}^{0.4} \\
\mathrm{c} \text { and } \mathrm{m} \text { are particle volume concentration dependent parameters. }\end{array}$ \\
\hline (Xuan and Li, 2003) & $\mathrm{CuO}$-water, turbulent & $\mathrm{Nu}=0.0059\left(1.0+7.6286 \phi_{\mathrm{p}}^{0.6886} \mathrm{Pe}_{\mathrm{p}}^{0.001}\right) \operatorname{Re}^{0.9238} \operatorname{Pr}^{0.4}$ \\
\hline (Yang et al., 2005) & $\begin{array}{l}\text { graphite-in-transmission fluid, } \\
\text { graphite-synthetic oil mixture, } \\
\text { laminar }\end{array}$ & $\begin{array}{l}\mathrm{Nu}=\mathrm{c} \operatorname{Re}^{\mathrm{m}} \operatorname{Pr}^{1 / 3}(\mathrm{D} / \mathrm{L})^{1 / 3}\left(\mu_{\mathrm{b}} / \mu_{\infty}\right)^{0.14} \\
\mathrm{c} \text { and } \mathrm{m} \text { are nanofluid and temperature dependent empirical } \\
\text { parameters. }\end{array}$ \\
\hline (Buongiorno, 2006) & turbulent & $\begin{array}{l}\mathrm{Nu}=\frac{(\mathrm{f} / 8)(\mathrm{Re}-1000) \mathrm{Pr}}{1+\delta_{\phi}^{+}(\mathrm{f} / 8)^{1 / 2}\left(\mathrm{Pr}_{\phi}^{2 / 3}-1\right)}, \\
\text { where the dimensionless thickness of the laminar sublayer } \sigma_{\phi}^{+} \text {is } \\
\text { an empirical parameter. }\end{array}$ \\
\hline (Polidori et al., 2007) & $\begin{array}{l}\mathrm{Al}_{2} \mathrm{O}_{3}, \text { Newtonian laminar, } \\
\text { natural convection }\end{array}$ & $\begin{array}{l}\mathrm{Nu}=\frac{4 \sqrt{5}}{3 \Delta_{\mathrm{nf}}}\left[\frac{\beta_{\mathrm{r}} \mathrm{k}_{\mathrm{r}}^{4}}{378 \mathrm{v}_{\mathrm{r}}^{2}\left(9 \Delta_{\mathrm{nf}}-5\right)} \mathrm{Gr}_{\mathrm{b}}\right]_{1 / 4}(\mathrm{UWT}) \\
\mathrm{Nu}=\frac{6}{5}\left[\frac{2 \beta_{\mathrm{r}} \mathrm{k}_{\mathrm{r}}^{4}}{27 \mathrm{v}_{\mathrm{r}}^{2}\left(9 \Delta_{\mathrm{nf}}-5\right) \Delta_{\mathrm{nf}}^{4}} \mathrm{Gr}_{\mathrm{b}}\right]_{1 / 5}(\mathrm{UWT}) \\
\Delta=\frac{\delta_{\mathrm{T}}}{\delta}=\frac{\text { thermal boundary layer thickness }}{\text { that of the dynamical one }}\end{array}$ \\
\hline
\end{tabular}




\section{NUMERICAL SIMULATION}

For numerical simulations two approaches have been adopted in the literature to investigate the heat transfer characteristics of nanofluids. The first approach assumes that the continuum assumption is still valid for fluids with suspended nano-size particles. The other approach uses a two-phase model for a better description of both the fluid and the solid phases, but it is not common in the open literature. The single phase model is much simpler and computationally more efficient. Another approach is to adopt the Boltzmann theory. The heat transfer enhancement using nanofluids may be affected by several factors such as the Brownian motion, layering at the solid/liquid interface, ballistic phonon transport through the particles, nanoparticle clustering and the friction between the fluid and the solid particles. It is difficult to describe all these phenomena mathematically, however.

Maïga et al. (2004a,b) numerically investigated the hydrodynamic and thermal characteristics of nanofluids flowing through a uniformly heated tube $(\mathrm{L}=1 \mathrm{~m})$ in both laminar and turbulent regimes using the single phase model with adjusted properties. Results showed that the addition of nanoparticles can increase the heat transfer substantially compared to the base fluid alone. It was also found that ethylene glycol- $\gamma \mathrm{Al}_{2} \mathrm{O}_{3}$ provided better heat transfer enhancement than water- $\gamma \mathrm{Al}_{2} \mathrm{O}_{3}$ nanofluids. However, Maïga et al. (2005) also discussed the disadvantages of nanofluids with respect to heat transfer. The inclusion of nanoparticles introduced drastic effects on the wall shear stress, which increased with an increase of the solid volume fraction. A new correlation was proposed by Maïga et al. (2006) to describe the thermal performance of $\mathrm{Al}_{2} \mathrm{O}_{3}$ /water nanofluids under turbulent regime, $\mathrm{Nu}_{\text {fully }}=0.085 \mathrm{Re}^{0.71} \operatorname{Pr}^{0.35}$, which is valid for $10^{4} \leq \operatorname{Re} \leq 5 \times 10^{5}, 6.6 \leq \operatorname{Pr} \leq 13.9$ and $0 \leq \phi \leq 10 \%$.

Roy et al. (2004) conducted a numerical study of heat transfer for water- $\gamma \mathrm{Al}_{2} \mathrm{O}_{3}$ nanofluids in a radial cooling system. They found that addition of nanoparticles in the base fluids increased the heat transfer rates considerably. Use of $10 \mathrm{vol} \%$ nanoparticles resulted in a two-fold increase of the heat transfer rate as compared to that of the pure base fluid. Their results are similar to those of Maiga et al. $(2004 a, b)$ since they both used the same model.

Wang et al. (2006) investigated numerically free convective heat transfer characteristics of a two- dimensional cavity over a range of Grashof numbers and solid volume fractions for various nanofluids. Their results showed that suspended nanoparticles significantly increased the heat transfer rate at all Grashof numbers. For water- $\gamma \mathrm{Al}_{2} \mathrm{O}_{3}$ nanofluid, the increase of the average heat transfer coefficient was approximately $30 \%$ for $10 \mathrm{vol} \%$ nanoparticles. The maximum increase in heat transfer performance of $80 \%$ was obtained for $10 \mathrm{vol} \% \mathrm{Cu}$ nanoparticles dispersed in water. Furthermore, the average heat transfer coefficient was seen to increase by up to $100 \%$ for a nanofluid consisting of oil containing 1 vol\% carbon nanotubes. Furthermore, the presence of nanoparticles in the base fluid was found to alter the structure of the fluid flow for horizontal orientation of the heated wall.

Khanafer et al. (2003) developed an analytical model to determine natural convective heat transfer in nanofluids. The nanofluid in the enclosure was assumed to be a single phase. The effect of suspended nanoparticles on a buoyancy-driven heat transfer process was analyzed. It was observed that the heat transfer rate increased as the particle volume fraction increased at any given Grashof number. Kim et al. (2004) analytically investigated the instability in natural convection of nanofluids by introducing a new factor (f), which measures the ratio of the Rayleigh number of the nanofluids to that of the base fluids, to describe the effect of nanoparticle addition on the convective instability and heat transport of the base fluid. Results demonstrated that the increased particle volume fraction improves the heat transfer rates in nanofluids compared to those in the base fluid alone.

Xuan and Roetzel (2000) derived several correlations for convective heat transfer of nanofluids. Both single phase and two phase models were used to explain the mechanism of the increased heat transfer rates. However, there are few experimental data to validate such models. Jang and Choi (2004a) investigated the natural stability of water-based nanofluids containing $6 \mathrm{~nm}$ copper and $2 \mathrm{~nm}$ diamond nanoparticles in a rectangular cavity heated from the bottom. They noted that nanofluids were more stable compared to the base fluids.

Recently, Abu-Nada (2008) numerically investigated heat transfer over a backward facing step (BFS) with nanofluids using the finite volume method. They found that the average Nusselt number increased with the volume fraction of nanoparticles for the whole range of Reynolds number $(200 \leq \operatorname{Re} \leq 600)$ studied. Numerical simulation of natural convection in horizontal concentric annuli, 
horizontal cylinder and a partially heated rectangular enclosure using nanofluids was also carried out by Abu-Nada et al. (2008a, 2008b) and Oztop et al. (2008), respectively. Results showed that, for nanoparticles such as $\mathrm{Cu}, \mathrm{Ag}, \mathrm{Al}_{2} \mathrm{O}_{3}$ and $\mathrm{TiO}_{2}$, the inclusion of different types and different volume fractions of nanoparticles in base fluid (water) had an adverse effect on heat transfer performance.

From the microscopic point of view, the traditional computational methods for two-phase mixture flow do not reveal the inherent nature of the fluid flow and heat transfer characteristics of nanofluids. A microscopic approach needs to be introduced to describe the effects of interactions between the suspended nanoparticles and the base liquid particles as well as among the solid particles. The lattice Boltzmann equation is one of the methods available to deal with such problems. By considering the external and internal forces on the nanoparticles and the mechanical and thermal interactions among the nanoparticle and fluid molecules, Xuan and Yao, (2005) simulated nanoparticle distributions and flow of nanofluids using the lattice Boltzmann model. The increased temperature of the fluids could increase the nanoparticle distribution, which is an important factor responsible for heat transfer enhancement in nanofluids. Xuan et al. (2005) observed that the random motion of nanoparticles tends to flatten the temperature distribution near the boundary wall. Due to the irregular fluctuation of suspended nanoparticles, the Nusselt distribution fluctuates along the main flow direction rather than exhibiting the smooth distribution of the base fluid. Their results indicated that the distribution and volume fraction of the nanoparticles were important factors determining the temperature distribution and heat transfer improvement with nanofluids.

Another interesting numerical investigation was conducted by Xue et al. (2004) using nonequilibrium molecular dynamics simulations. They studied the effect of the liquid-solid interface on the interfacial thermal resistance and found that the simple monatomic liquid around the solid particle had no influence on the thermal transport either normal to the surface or parallel to the surface. They suggested that the large improvement of thermal conductivity in nanofluids cannot be explained by thermal transport in the liquid-solid interface layer.

In summary, it is difficult to identify an established theory to predict accurately the heat transfer characteristics of nanofluids. Many researchers deal with nanofluids as a single-phase fluid rather than a two-phase mixture. However, the particle-liquid interaction and the movement between the particle and liquids should play important roles in affecting the convective heat transfer performance of nanofluids.

\section{NOMENCLATURE}

$\begin{array}{llr}\mathrm{A} & \begin{array}{l}\text { constant } \\ \text { depolarization factor along }\end{array} & (-) \\ \mathrm{B}_{2, \mathrm{x}} & \begin{array}{l}(-) \\ \text { the x- symmetrical axis }\end{array} \\ \mathrm{D} & \begin{array}{l}\text { diameter of tube, mm } \\ \text { diameter of particle }\end{array} & (-) \\ \mathrm{d} & \text { height of discs, mm } & (-) \\ \mathrm{H} & \text { heat transfer coefficient, } & \mathrm{W} / \mathrm{m}^{2}-\mathrm{K} \\ \mathrm{h} & \mathrm{W} / \mathrm{m}-\mathrm{K} \\ \mathrm{k} & \text { thermal conductivity } & \mathrm{k} / \mathrm{K} \\ \mathrm{k}_{\mathrm{B}} & \text { Boltzmann constant } & \left(-381 \times 10^{-23}\right. \\ & & \mathrm{mm} \\ \mathrm{k}_{\mathrm{c}, \mathrm{j}} & \text { effective dielectric constant } & (-) \\ \mathrm{L} & \text { length of tube } & \mathrm{n}=3 / \psi \\ \mathrm{m} & \text { constant } & (-) \\ \mathrm{n} & \text { empirical shape factor } & \mathrm{Nu}=\mathrm{hD} / \mathrm{k} \\ \mathrm{n}(\mathrm{r}) & \text { radius distribution function } & \mathrm{Pe}=\rho \mu \mathrm{L} / \Gamma \\ \mathrm{Nu} & \text { Nusselt number } & \mathrm{Pr}=\mathrm{C}_{\mathrm{p}} \mu / \mathrm{k} \\ \mathrm{Pe} & \text { Peclet number } & (-) \\ \mathrm{Pr} & \text { Prandtl number } & \mathrm{Re}=\rho \mathrm{VD} / \mu \\ \mathrm{r}_{\mathrm{c}} & \text { apparent radius of clusters } & \mathrm{K} \\ \mathrm{Re} & \text { Reynolds number } & \\ \mathrm{T} & \text { temperature } & \end{array}$

\section{Greek Symbols}

$\alpha \quad$ aspect ratio of nanoparticles

$\beta \quad$ ratio of the nanolayer thickness to the original particle radius

$\gamma \quad$ ratio of nanolayer thermal $\quad \gamma=\mathrm{k}_{\text {layer }} / \mathrm{k}_{\mathrm{p}}$ conductivity to particle

$\mathrm{N} / \mathrm{m}-\mathrm{K}$ $\mathrm{J} / \mathrm{K}$

$\mathrm{K}$

thermal conductivity

$v \quad$ dynamic viscosity

$\phi \quad$ volume fraction of nanoparticles in suspension

$\psi \quad$ particle sphericity

\section{Subscripts}

$\begin{array}{ll}\mathrm{b} & \text { base fluid } \\ \mathrm{cl} & \text { cluster of particles } \\ \text { eff } & \text { effective } \\ \text { in } & \text { inner tube } \\ \mathrm{nf} & \text { nanofluid }\end{array}$




$$
\begin{array}{ll}
\text { out } & \text { outer tube } \\
\text { pe } & \text { modified nanoparticle } \\
\text { p } & \text { nanoparticle }
\end{array}
$$

\section{REFERENCES}

Abu-Nada, E. Application of nanofluids for heat transfer enhancement of separated flows encountered in a backward facing step. International Journal of Heat and Fluid Flow, 29, no. 1, 242-249 (2008).

Abu-Nada, E., Masoud, Z., Hijazi, A. Natural convection heat transfer enhancement in horizontal concentric annuli using nanofluids. Int. Communications in Heat and Mass Transfer, 35, no. 5, 657-665 (2008).

Abu-Nada, E., Ziyad, K., Saleh, M., Ali, Y. Enhancement of heat transfer in combined convection around a horizontal cylinder. ASME Journal of Heat Transfer, Doi: 10.1115/1.2909616 (2008).

Batchelor, G. The effect of Brownian motion on the bulk stress in a suspension of spherical particles. Journal of Fluid Mechanics, 83, 97-117 (1977).

Bhattacharya, P., Saha, S. K., Yadav, A., Phelan, P. E., and Prasher, R.S. Brownian dynamics simulation to determine the effective thermal conductivity of nanofluids. Journal of Applied Physics, 95, no. 11, 6492-6494 (2004).

Brinkman, H. C. The Viscosity of Concentrated Suspensions and Solutions. Journal of Chemical Physics, 20, 571 (1952).

Bruggeman, D. A. G. Berechnung verschiedener physikalischer konstanten von heterogenen substanzen, I. Dielektrizitatskonstanten und leitfahigkeiten der mischkorper aus isotropen substanzen. Annalen der Physik, Leipzig, 24, 636-679 (1935).

Buongiorno, J. Convective transport in nanofluids. Journal of Heat Transfer, 128, 240-250 (2006).

Choi, S. U.S. Enhancing thermal conductivity of fluids with nanoparticles. Developments and Applications of Non-Newtonian Flows, FED-Vol. 231/MD-Vol. 66, 99-105 (1995).

Choi, S. U. S., Zhang, Z. G., Yu, W., Lockwood, F. E., and Grulke, E. A. Anomalous thermal conductivity enhancement in nano-tube suspensions. Applied Physics Letters, 79, 2252-2254 (2001).

Das, S. K., Putra, N., and Roetzel, W. Pool boiling characteristics of nano-fluids. International Journal of Heat and Mass Transfer, 46, no. 5, 851-862 (2003a).
Das, S. K., Putta, N., Thiesen, P., and Roetzel, W. Temperature dependence of thermal conductivity enhancement for nanofluids. ASME Trans. J. Heat Transfer, 125, 567-574 (2003b).

De Bruijn, H. The viscosity of suspensions of spherical particles. Recueil des travaux chimiques des Pays-Bas, 61, 863-874 (1942).

Ding, Y. and Wen, D. Particle migration in a flow of nanoparticle suspensions. Powder Technology, 149, no. 2-3, 84-92 (2005).

Dittus, F. and Boelter, L. Heat transfer in automobile radiators of the tubular type. University of California Publications in Engineering, 2, 443461 (1930).

Eastman, J. A., Phillpot, S. R., Choi, S. U. S., and Keblinski, P. Thermal transport in nanofluids. Annu. Rev. Mater. Res., 34, 219-46 (2004).

Eilers, v. H. Die viskocitat von emulsionen hochviskoser stoffe als funktion der konzentration. Kolloid-Zeitschrift, 97, 313-321 (1941).

Einstein, A. Eine neue bestimmung der molekuldimensionen. Annalen der Physik, Leipzig, 19, 289-306 (1906).

Einstein, A. Investigation on theory of Brownian motion. Dover, New York (1956).

Eshelby, J. The determination of the elastic field of an ellipsoidal inclusion, and related problems. In Proceedings of Royal Society of London, volume A241, 376-396 (1957).

Evans, W., Fish, J., and Keblinski, P. Role of Brownian motion hydrodynamics on nanofluid thermal conductivity. Applied Physics Letters, 88, no. 9, 93,116-1-3 (2006).

Frankel, N. and Acrivos, A. On the viscosity of concentrated suspension of solid spheres. Chemical Engineering Science, 22, 847-853 (1967).

Gao, L. and Zhou, X. F. Differential effective medium theory for thermal conductivity in nanofluids. Physics Letters A, In Press, Corrected Proof (2005).

Gnielinski, V. New equations for heat and mass transfer in turbulent pipe and channel flow. International Chemical Engineering, 16, 359-368 (1976).

Graham, A. On the viscosity of suspensions of solid spheres. Applied Scientific Research, 37, 275286 (1981).

Hamilton, R. L. and Crosser, O. K. Thermal conductivity of heterogeneous two-component systems. I\&EC Fundam, 1, 182-191 (1962).

Jang, S. P. and Choi, S. U. S. Free convection in a rectangular cavity (Benard convection) with 
nanofluids. In Proceedings of IMECE, 13-19. Anaheim, California, USA (2004a).

Jang, S. P. and Choi, S. U. S. Role of Brownian motion in the enhanced thermal conductivity of nanofluids. Applied Physics Letters, 84, 43164318 (2004b).

Keblinski, P., Eastman, J. A., and Cahill, D. G. Nanofluids for thermal transport. Materials Today, 8, no. 6, 36-44 (2005).

Keblinski, P., Phillpot, S. R., Choi, S. U. S., and Eastman, J. A. Mechanisms of heat flow in suspensions of nano-sized particles (nanofluids). International Journal of Heat and Mass Transfer, 45, 855-863 (2002).

Khaled, A. R. A. and Vafai, K. Heat transfer enhancement through control of thermal dispersion effects. International Journal of Heat and Mass Transfer, 48, no. 11, 2172 (2005).

Khanafer, K., Vafai, K., and Lightstone, M. Bouyancy-driven heat transfer enhancement in a two-dimensional enclosure utilizing nanofluids. International Journal of Heat and Mass Transfer, 46, 3639-3653 (2003).

Kim, J., Kang, Y. T., and Choi, C. K. Analysis of convective instability and heat transfer characteristics of nanofluids. Physics of Fluids, 16, no. 7, 2395-2401 (2004).

Koo, J. and Kleinstreuer, C. A new thermal conductivity model for nanofluids. Journal of Nanoparticle Research, 6, no. 6, 577-588 (2004

Koo, J. and Kleinstreuer, C. Impact analysis of nanoparticle motion mechanisms on the thermal conductivity of nanofluids. International Communications in Heat and Mass Transfer, 32, no. 9, 1111-1118 (2005a).

Koo, J. and Kleinstreuer, C. Laminar nanofluid flow in micro-heat sinks. International Journal of Heat and Mass Transfer, 48, no. 13, 2652-2661 (2005b).

Krieger, I. Rheology of monodisperse lattices. Advances in Colloid and Interface Sciences, 3, 111-136 (1972).

Kuhn, W. and Kuhn, H. Abhangigkeit der viskositat vom stromungsgefalle bei hochverdunnten suspensionen und losungen. Helvetica Chimica Acta, 28, 97-127 (1945).

Kulkarni, D. P., Das, D. K., and Chukwu, G. Temperature dependent rheological property of copper oxide nanoparticles suspension (Nanofluid). Journal of Nanoscience and Nanotechnology, 6, 1150-1154 (2006).

Kumar, D. H., Patel, H. E., Kumar, V. R. R., Sundararajan, T., Pradeep, T., and Das, S. K. Model for heat conduction in nanofluids. Physical
Review Letters, 93, no. 14, 144,301-1-144,301-4 (2004).

Lee, D., Kim, J.-W., and Kim, B. G. A new parameter to control heat transport in nanofluids: Surface charge state of the particle in suspension. Journal of Physical Chemistry B, 110, no. 9, 4323-4328 (2006).

Lee, S., Choi, S. U. S., Li, S., and Eastman, J. A. Measuring thermal conductivity of fluids containing oxide nanoparticles. Journal of Heat Transfer, 121, 280-289 (1999).

Lundgren, T. Slow flow through stationary random beds and suspensions of spheres. Journal of Fluid Mechanics, 51, 273-299 (1972).

Maiga, S. E. B., Cong Tam, N., Galanis, N., Roy, G., Mare, T., and Coqueux, M. Heat transfer enhancement in turbulent tube flow using $\mathrm{Al}_{2} \mathrm{O}_{3}$ nanoparticle suspension. International Journal of Numerical Methods for Heat and Fluid Flow, 16, no. 3, 275-292 (2006).

Maiga, S. E. B., Nguyen, C. T., Galanis, N., and Roy, G. Heat transfer behaviours of nanofluids in a uniformly heated tube. Superlattices and Microstructures, 35, 543-557 (2004a).

Maiga, S. E. B., Nguyen, C. T., Galanis, N., and Roy, G. Hydrodynamic and thermal behaviours of a nanofluid in a uniformly heated tube. volume 5 of Computational Studies, 453-462. WIT Press, Southampton, SO40 7AA, United Kingdom, Lisbon, Portugal (2004b).

Maiga, S. E. B., Palm, S. J., Nguyen, C. T., Roy, G., and Galanis, N. Heat transfer enhancement by using nanofluids in forced convection flows. International Journal of Heat and Fluid Flow, 26, no. 4, 530-546 (2005).

Mandelbrot, B. B. The Fractal Geometry of Nature. W. H. Freeman Press, San Francisco (1982).

Mansour, R. B., Galanis, N., and Nguyen, C. T. Effect of uncertainties in physical properties on forced convection heat transfer with nanofluids. Applied Thermal Engineering, 27, no. 1, 240-249 (2007).

Maxwell, J. C. A Treatise on Electricity and Magnetism. Clarendon Press, Oxford, UK, second edition (1881).

Mooney, M. The viscosity of a concentrated suspension of spherical particles. Journal of Colloid Science, 6, 162-170 (1951).

Nan, C.-W., Liu, G., Lin, Y., and Li, M. Interface effect on thermal conductivity of carbon nanotube composites. Applied Physics Letters, 85, 35493551 (2004).

Nan, C.-W., Shi, Z., and Lin, Y. A simple model for thermal conductivity of carbon nanotube-based 
composites. Chemical Physics Letters, 375, no. 5-6, 666-669 (2003).

Oztop, H., Abu-Nada, E., Numerical study of natural convection in a partially heated rectangular enclosure filled with nanofluids, International Journal of Heat and Fluid Flow, Doi: 10.1016/j.ijheatfluidflow.2008.02.009 (2008).

Pak, B. and Cho, Y. Hydrodynamic and heat transfer study of dispersed fluids with submicron metallic oxide particles. Experimental Heat Transfer, 11, no. 2, 151-170 (1998).

Patel, H. E., Das, S. K., Sundararagan, T., Nair, A. S., Geoge, B., and Pradeep, T. Thermal conductivities of naked and monolayer protected metal nanoparticle based nanofluids: Manifestation of anomalous enhancement and chemical effects. Applied Physics Letters, 83, 2931-2933 (2003).

Polidori, G., Fohanno, S., and Nguyen, C. T. A note on heat transfer modelling of Newtonian nanofluids in laminar free convection. International Journal of Thermal Sciences, 46, no. 8, 739-744 (2007).

Prasher, R., Bhattacharya, P., and Phelan, P.E. Thermal conductivity of nanoscale colloidal solutions (nanofluids). Physical Review Letters, 94, no. 2, 025,901/1-4 (2005).

Putnam, S. A., Cahill, D. G., Braun, P. V., Ge, Z., and Shimmin, R. G. Thermal conductivity of nanoparticle suspensions. Journal of Applied Physics, 99, no. 8, 084,308 (2006).

Robinson, J. The viscosity of suspensions of spheres. Journal of Physical and Colloid Chemistry, 53, 1042-1056 (1949).

Roy, G., Nguyen, C. T., and Lajoie, P.-R. Numerical investigation of laminar flow and heat transfer in a radial flow cooling system with the use of nanofluids. Superlattices and Microstructures, 35, 497-511 (2004).

Saito, N. Concentration dependence of the viscosity of high polymer solutions. Journal of the Physical Society of Japan, I., 5, 4-8 (1950).

Schwartz, L., Garboczi, E., and Bentz, D. Interfacial transport in porous media: Application to DC electrical conductivity of mortars. Journal of Applied Physics, 78, no. 10, 5898-5908 (1995).

Simha, R. The influence of Brownian movement on the viscosity of solutions. Journal of Physical Chemistry, 44, 25-34 (1940).

Simha, R. A treatment of the viscosity of concentrated suspensions. Journal of Applied Physics, 23, 1020-1024 (1952).

Tillman, P. and Hill, J. M. Determination of nanolayer thickness for a nanofluid. International
Communications in Heat and Mass Transfer, In Press, Uncorrected Proof (2007).

Tseng, W. and Lin, K.-C. Rheology and colloidal structure of aqueous $\mathrm{TiO}_{2}$ nanoparticle suspensions. Material Science and Engineering: A, 355, 186192 (2003).

Vadasz, P. Heat conduction in nanofluid suspensions. Transactions of the ASME. Journal of Heat Transfer, 128, no. 5, 465-477 (2006).

Vand, V. Viscosity of solutions and suspensions. Journal of Physical and Colloid Chemistry, I. Theory., 52, 277-299 (1948).

Wang, B.-X., Zhou, L.-P., and Peng, X.-F. A fractal model for predicting the effective thermal conductivity of liquid with suspension of nanoparticles. International Journal of Heat and Mass Transfer, 46, 2665-2672 (2003).

Wang, X., Xu, X., and Choi, S. U.S. Thermal conductivity of nanoparticle-fluid mixture. Journal of Thermophysics and Heat Transfer, 13, no. 4, 474-480 (1999).

Wang, X.-Q., Mujumdar, A. S., and Yap, C. Free Convection Heat Transfer in Horizontal and Vertical Rectangular Cavities Filled with Nanofluids. In International Heat Transfer Conference IHTC-13. Sydney, Australia (2006).

Wasp, E. J., Kenny, J. P., and Gandhi, R. L. Solidliquid slurry pipeline transportation. Bulk Materials Handling. Trans Tech Publications, Germany. (1999).

Wen, D. and Ding, Y. Effect of particle migration on heat transfer in suspensions of nanoparticles flowing through minichannels. Microfluidics and Nanofluidics, 1, no. 2, 183-189 (2005).

Xie, H., Fujii, M., and Zhang, X. Effect of interfacial nanolayer on the effective thermal conductivity of nanoparticle-fluid mixture. International Journal of Heat and Mass Transfer, 48, no. 14, 29262932 (2005).

Xie, H., Lee, H., Youn, W., and Choi, M. Nanofluids containing multiwalled carbon nanotubes and their enhanced thermal conductivities. Journal of Applied Physics, 94, no. 8, 4967-4971 (2003).

Xuan, Y. and Li, Q. Heat transfer enhancement of nanofluids. International Journal of Heat and Fluid Transfer, 21, 58-64 (2000).

Xuan, Y. and Li, Q. Investigation on convective heat transfer and flow features of nanofluids. Journal of Heat Transfer, 125, 151-155 (2003).

Xuan, Y., Li, Q., and Hu, W. Aggregation structure and thermal conductivity of nanofluids. AIChE Journal, 49, no. 4, 1038-1043 (2003).

Xuan, Y. and Roetzel, W. Conceptions for heat 
transfer correlation of nanofluids. International Journal of Heat and Mass Transfer, 43, 37013707 (2000).

Xuan, Y. and Yao, Z. Lattice boltzmann model for nanofluids. Heat and Mass Transfer/Waerme- und Stoffuebertragung, 41, no. 3, 199-205 (2005).

Xuan, Y., Yu, K., and Li, Q. Investigation on flow and heat transfer of nanofluids by the thermal Lattice Boltzmann model. Progress in Computational Fluid Dynamics, 5, no. 1/2, 13-19 (2005).

Xue, L., Keblinski, P., Phillpot, S. R., Choi, S. U. S., and Eastman, J. A. Effect of liquid layering at the liquid-solid interface on thermal transport. International Journal of Heat and Mass Transfer, 47, no. 19-20, 4277-4284 (2004).

Xue, Q. Model for the effective thermal conductivity of carbon nanotube composites. Nanotechnology, 17, no. 6, 1655-60 (2006).

Xue, Q. and $\mathrm{Xu}, \mathrm{W} .-\mathrm{M}$. A model of thermal conductivity of nanofluids with interfacial shells. Materials Chemistry and Physics, 90, no. 2-3,
298-301 (2005).

Xue, Q.-Z. Model for effective thermal conductivity of nanofluids. Physics Letters A, 307, 313-317 (2003).

Xue, Q. Z. Model for thermal conductivity of carbon nanotube-based composites. Physica B: Condensed Matter, 368, no. 1-4, 302-307 (2005).

Yang, Y., Zhang, Z. G., Grulke, E. A., Anderson, W. B., and $\mathrm{Wu}, \mathrm{G}$. Heat transfer properties of nanoparticle-in-fluid dispersions (nanofluids) in laminar flow. International Journal of Heat and Mass Transfer, 48, no. 6, 1107-1116 (2005).

$\mathrm{Yu}$, W. and Choi, S. U.S. The role of interfacial layers in the enhanced thermal of nanofluids: a renovated Maxwell model. Journal of Nanoparticle Research, 5, no. 1-2, 167-171 (2003).

$\mathrm{Yu}, \mathrm{W}$. and Choi, S. U. S. The role of interfacial layers in the enhanced thermal conductivity of nanofluids: A renovated Hamilton-Crosser model. Journal of Nanoparticle Research, 6, no. 4, 355361 (2004). 